Int. J. Morphol.,

35(2):529-532, 2017

\title{
Simple and Low Cost Tridimensional Model of the Cerebral Hemisphere
}

\author{
Modelo Tridimensional Básico y de Bajo Costo del Hemisferio Cerebral
}

Carlos R. Rueff-Barroso ${ }^{1,2}$; Karina Seixas Garcia ${ }^{1}$; Kamila da Silva Peruzini'
Caroline Fernandes-Santos

RUEFF-BARROSO, C. R.; GARCIA, K. S.; PERUZINI, K. S.; FERNANDES-SANTOS, C. \& PEREIRA-SAMPAIO, M. A. Simple and low cost tridimensional model of the cerebral hemisphere. Int. J. Morphol., 35(2):529-532, 2017.

SUMMARY: Handmade anatomy models may be a complementary useful tool to dissection and prosection, since the student interacts with the body structure in a three-dimensional way. In this study homemade dough (biscuit) was used to create a brain model. Two anatomy trainees from the medical school of the Universidade Federal Fluminense (Niteroi Brazil) were challenged to model the gross anatomy of the lateral aspect of the brain. They prepared and handled homemade dough to produce a simple and low cost model of the cerebral hemisphere. Styrofoam balls fixed by pins were used to create a framework, and dough rolls were modeled in order to create the brain sulci and gyri.At the end, the model closely resembled three-dimensional features of the human brain. Also, brain lobes were easily identified, as well as some major gyri and sulci, such as the central and lateral sulci and the precentral and postcentral gyri. In conclusion, the three-dimensional spatial characteristics, the clear identification of sulci and gyri and the brain lobes, make this model a good tool for students who only require basic anatomy in their curriculum.

KEY WORDS: Simple anatomy models; Brain; Neuroanatomy.

\section{INTRODUCTION}

Anatomy is usually taught in laboratories by means of dissecting or inspections/demonstrations of human cadavers. The students need to stay in the lab for many hours to memorize several structures of the body, which they must learn and know (Donelan, 2000). When anatomy learning is passive, students tend to memorize names and functions for a short time, but do not always build a long term memory. Students can be challenged to design and create models, as an alternative to help the understanding of anatomy (Donelan).

Cadavers have been used routinely in anatomy teaching as a gold standard, however, they are not easily obtained due to ethical/legal difficulties (McLachlan, 2004; McLachlan et al., 2004). Besides, the students only have the opportunity to study anatomy in cadavers while in the labs, where the smell of the usual fixative solutions is unpleasant and hazardous (Checkoway et al., 2012). Finally, the maintenance of a facility to keep cadavers is expensive and hardworking.

The virtual image models offered for the students are two-dimensional, even when they were made tridimensional in screens (de Ribaupierre \& Wilson, 2012), because they cannot handle the images. The creation of a handmade anatomy model by students may be a complimentary practice to dissection and prosection, since the student will interact with the model of a body structure in a three-dimension setting. Play dough was used to provide temporary model for nervous system (Eftekhar et al., 2005; Herur et al., 2011). The modeling of cold porcelain or biscuit is a handmade technique that has been largely used professionally by different professionals as a source of foundation and support to prepare permanent sculptures. Since the regular biscuit was too delicate and had low robustness and durability, handicraftsmen added other materials such as glue to turn it stronger. It also allows the application of paints, making them highlight their brightness.

The present work aimed to challenge two anatomy trainee students from the medical school to build a cerebral hemisphere model made of homemade dough (biscuit) that resemble a real brain under professor supervision. Finally, the model would be used as a complimentary material for students who require knowledge of basic anatomy in their curriculum.

\footnotetext{
${ }^{1}$ Department of Morphology, Biomedical Institute, Universidade Federal Fluminense, Niterói, Rio de Janeiro, Brazil.

${ }^{2}$ Department of Morphology, Health Sciences Center, Federal University of Espírito Santo, Vitória, Espírito Santo, Brazil.

${ }^{3}$ Department of Basic Sciences, Campus of Nova Friburgo, Universidade Federal Fluminense, Nova Friburgo, Rio de Janeiro, Brazil.
} 


\section{MATERIAL AND METHOD}

The brain model was created by two trainees from the Medical School of the Universidade Federal Fluminense, Niteroi, RJ, Brazil. Homemade dough consisted of two cups of white glue, two cups of corn starch, two tablespoons of liquid vaseline, and one tablespoon of lime juice. Before heating, all ingredients were mixed in a pan using a wood spoon. Then, the paste was mixed continuously on low heat until it sticks on the wood spoon but not to the bottom of the pan. The dough was then rolled in a polished and cold surface using approximately one tablespoon of moisturizing free of silicon to help spreading. The dough was promptly covered with a plastic film and it was left to rest overnight.

To build the cerebral hemisphere, styrofoam balls of different sizes fixed by pins were used to create a framework to give the initial shape of the model (Fig. 1AB). A thin layer of dough was used to cover the framework to make it smooth (Fig. 1C). Finally, dough rolls (Fig. 1DF) were placed over it in accordance with the brain lobes (Fig. 2) based on the Netter Atlas of Human Anatomy (Netter, 2006). A water based acrylic ink (Acrilex, São Paulo, SP, Brazil) was used to paint the brain lobes with different colors (Fig. 3).
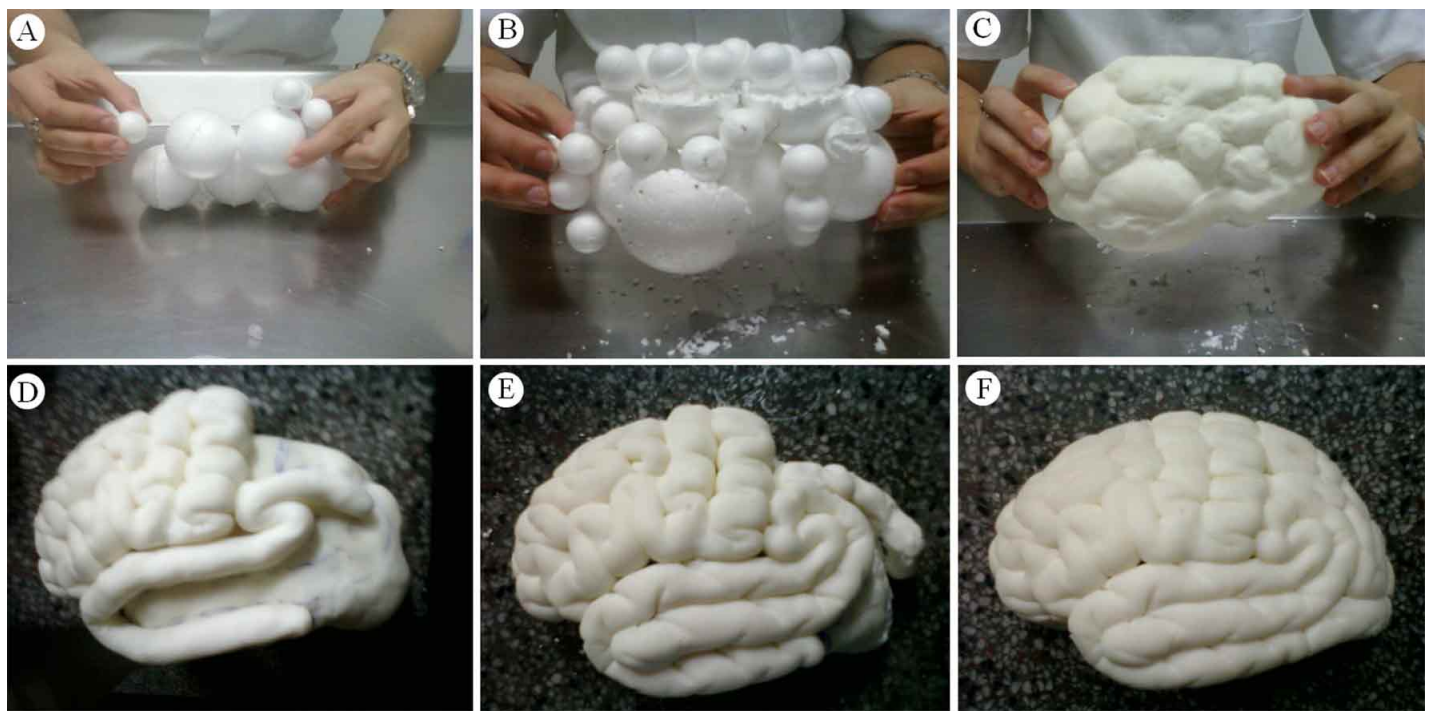

Fig. 1. This picture illustrates the steps to create a handmade brain model using homemade dough. A-B. Styrofoam balls of varying sizes fixed by pins were used to create a framework. C. Thin layer of dough spread over the styrofoam. D-E. Dough rolls were modeled according to brain sulci and gyri. F. The handmade brain model created by the trainees closely resembles the human brain.

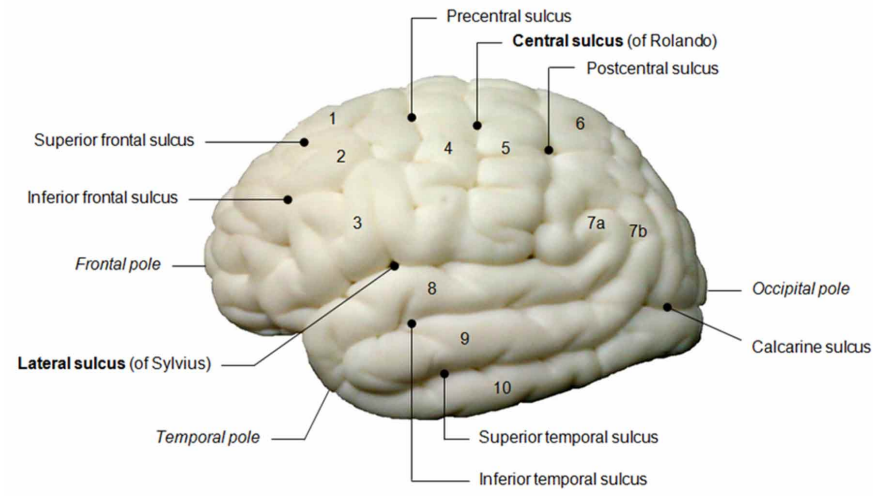

Fig. 2. The handmade brain model showing several structures, such as (1) superior frontal gyrus; (2) middle frontal gyrus; (3) inferior frontal gyrus; (4) precentral gyrus; (5) postcentral gyrus; (6) superior parietal lobule; (7a) inferior parietal lobule - supramarginal gyrus; (7b) inferior parietal lobule angular gyrus; (8) superior temporal gyrus; (9) middle temporal gyrus and; (10) inferior temporal gyrus.

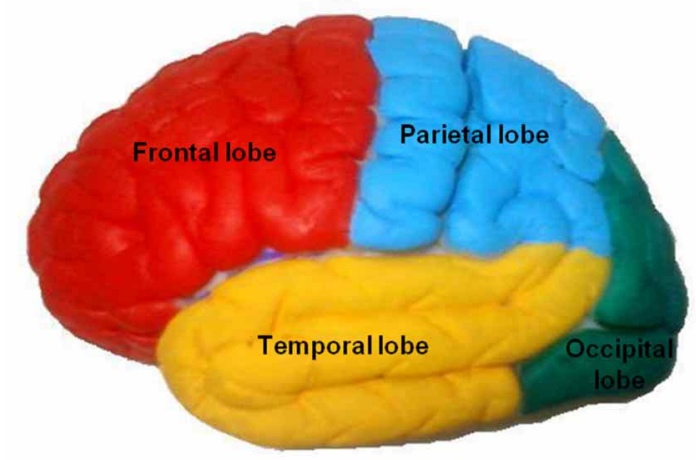

Fig. 3. The handmade brain model showing the brain lobes painted with different colors to make easier the identification. 


\section{RESULTS}

The technique used to produce the model was satisfactory. The framework of styrofoam balls gave the necessary support for modeling of sulci and gyri of the brain. The homemade dough worked well to prepare the brain surface, allowing painting. After the complete setting off, the model became strong enough to be handled.

The students spent less than 30 minutes to prepare the dough and had to wait until next day to begin the modeling. The model preparation took less than 1 hour, but took two more days to complete the hardening of the dough.

The simple brain model, built with the homemade dough, is presented in Figure 2, where the gross anatomy of the left cerebral hemisphere is shown. It is clearly noticed that the model is similar to the human brain hemisphere surface, mainly to identification of some individual gyri and sulci, such as the central sulcus delimiting the frontal and parietal lobes, as well as the precentral and postcentral gyri. The presence of the calcarine sulcus in the occipital lobe is also clear, as well as the lateral sulcus between the parietal and temporal lobes. In Figure 3, the brain lobes were highlighted using different colors for each one, using the gyri and sulci to determine their boundaries.

\section{DISCUSSION}

The handmade anatomy models did not completely correspond to the real human body, but they could be used as a complementary tool for students of health science courses, who require only the basic anatomy in their curriculum. We achieved the reproduction of the brain surface in a simple model. In Figure 2 it is possible to recognize all gyri and sulcus located at the lateral aspect of the human brain. It could be used to correlate anatomical areas with the major functional somatic motor and sensorial areas of the brain and other functional areas of the human brain. As demonstrated in Figure 3, where the brain lobes were painted with different colors, functional areas of the brain could be highlighted, for example the primary and secondary motor and sensory areas, the visual area, the speech and auditory areas. So, this preparation could be useful in different courses depending on what the students will be taught. Depending on the students, just naming the lobes may be sufficient, or the students may be required to know the names of the specific gyri and sulci, or the students could correlate the anatomy with the functional areas of the brain.
Regarding the technique, we prepared the homemade dough and it took some time. On the other hand, the commercial dough could be used to save time during the preparation, but it is more expensive. Students had fun preparing the homemade dough, and they made it in a short period of time with supervision. Beginners without supervision might take more time to learn the ideal consistency. In contrast, the commercial dough is ready to use, thus saving time.

The handmade model has some advantages when compared with the commercial plastic models, such as lower cost, and the learning that can occur during the tactile and kinesthetic procedure of making the models. Thus, the time consuming in model preparation can be useful for student learning, because during the preparation of the model the student has to learn and understand the structure that will be represented in detail, and then handle the dough. Modeling is not a fast step, since the student needs solve how the dough should be modeled, in order to acquire a shape similar to the real structure. This process takes time and helps the consolidation of a long term memory. The lower cost can also justify the time consuming to prepare the homemade dough and the handmade model. In contrast, we can also see some disadvantages, such as time consuming and durability. If each student in the class was given the task to make the model, as beginners it would take quite a bit of tutorial time, considering that time must also be taken to appreciate the craft, the consistency of the material and the difficulty of the process, the number of hours assigned could be excessive. The handmade model prepared with homemade dough is not temporary as models prepared with clay (Motoike et al., 2009), and can be used many times, but our models do not last long as the plastic models. Again, the lower cost can justify the lesser durability.

A recent review on the educational value of handmade anatomical models highlighted the strong correspondence in the spatial relationship between the models and the human body, even when it does not resemble all details of the structure that it is representing. Thus, the handmade anatomical models could help students to get threedimension comprehension of anatomical structures (Chan \& Cheng, 2011). It is already known that dissection gives students a three-dimension perception on the human body and reinforces the knowledge acquired in lectures and tutorials (Jones, 1997; Aziz et al., 2002; Gregory \& Cole, 2002). During production the handmade model, students will also come across some difficulties resembling those encountered during dissection, since they will be dealing with three-dimensional structures. Thus, this kind of activity might also reinforce the knowledge acquired during lectures and tutorials. 


\section{CONCLUSION}

Despite the handmade model not faithfully representing all features of the cerebral hemisphere, the threedimensional spatial characteristics, the clear identification of sulci and gyri and the brain lobes, make this model a good tool for students who only require basic anatomy.

\section{ACKNOWLEDGMENTS}

We are thankful to Marina Caliari, an artist who provided us with documents regarding the history, methods and secrets about the homemade dough. The authors are grateful to Valéria Paula Sassoli Fazan for her suggestions and reviewing the final version of the manuscript.

RUEFF-BARROSO, C. R.; GARCIA, K. S.; PERUZINI, K. S.; FERNANDES-SANTOS, C. \& PEREIRA-SAMPAIO, M. A. Modelo tridimensional simple y de bajo costo del hemisferio cerebral. Int. J. Morphol., 35(2):529-532, 2017.

RESUMEN: Los modelos de anatomía elaborados a mano pueden ser una herramienta útil y complementaria a la disección y la prosección, debido a que el alumno interactúa con la estructura del cuerpo de manera tridimensional. En este estudio se utilizó una masa casera (bizcocho) para crear un modelo cerebral. Dos estudiantes de anatomía de la Facultad de Medicina de la Universidade Federal Fluminense (Niteroi, Brasil) fueron desafiados a modelar la anatomía macroscópica de la cara lateral del cerebro. Prepararon y manejaron masa casera para producir un modelo simple y de bajo costo del hemisferio cerebral. Bolas de espuma de poliestireno fijado por alfileres se utilizaron para crear un marco, y los rollos de masa fueron modelados con el fin de crear los surcos cerebrales y giros. Al final, el modelo resultó ser muy semejante a las características tridimensionales del cerebro humano. Además, los lóbulos cerebrales fueron fácilmente identificados, así como algunos giros y surcos mayores, tales como el surco central y lateral y el giro precentral y postcentral. En conclusión, las características espaciales tridimensionales, la identificación clara de los surcos y giros y los lóbulos cerebrales, hacen de este modelo una buena herramienta para los estudiantes que sólo requieren anatomía básica en su plan de estudios.

PALABRAS CLAVE: Modelos anatómicos básicos; Cerebro; Neuroanatomía.

\section{REFERENCES}

Aziz, M. A.; McKenzie, J. C.; Wilson, J. S.; Cowie, R. J.; Ayeni, S. A. \& Dunn, B. K. The human cadaver in the age of biomedical informatics. Anat. Rec., 269(1):20-32, 2002.

Chan, L. K. \& Cheng, M. M. W. An analysis of the educational value of low-fidelity anatomy models as external representations. Anat. Sci. Educ., 4(5):256-63, 2011.

Checkoway, H.; Boffetta, P.; Mundt, D. J. \& Mundt, K. A. Critical review and synthesis of the epidemiologic evidence on formaldehyde exposure and risk of leukemia and other lymphohematopoietic malignancies. Cancer Causes Control, 23(11):1747-66, 2012.

de Ribaupierre, S. \& Wilson, T. D. Construction of a 3-D anatomical model for teaching temporal lobectomy. Comput. Biol. Med., 42(6):692-6, 2012.

Donelan, S. Creative anatomy teaching. Wilderness Environ. Med., 11(4):276-9, 2000.

Eftekhar, B.; Ghodsi, M.; Ketabchi, E. \& Ghazvini, A. R. Play dough as an educational tool for visualization of complicated cerebral aneurysm anatomy. B. M. C. Med. Educ., 5:15, 2005.

Gregory, S. R. \& Cole, T. R. MSJAMA. The changing role of dissection in medical education. JAMA, 287(9):1180-1, 2002.

Herur, A.; Kolagi, S.; Chinagudi, S.; Manjula, R. \& Patil, S. Active learning by play dough modeling in the medical profession. Adv. Physiol. Educ., 35(2):241-3, 2011.

Jones, D. G. Reassessing the importance of dissection: a critique and elaboration. Clin. Anat., 10(2):123-7, 1997.

McLachlan, J. C. New path for teaching anatomy: living anatomy and medical imaging vs. dissection. Anat. Rec. B New Anat., 281(1):4-5, 2004.

McLachlan, J. C.; Bligh, J.; Bradley, P. \& Searle, J. Teaching anatomy without cadavers. Med. Educ., 38(4):418-24, 2004.

Motoike, H. K.; O'Kane, R. L.; Lenchner, E. \& Haspel, C. Clay modeling as a method to learn human muscles: A community college study. Anat. Sci. Educ., 2(1):19-23, 2009.

Netter, F. H. Atlas of Human Anatomy. $4^{\text {th }}$ ed. Philadelphia, Saunders Elsevier, 2006.

Corresponding author:

Carlos R. Rueff-Barroso

Av. Marechal Campus

1468, Prédio Básico 2, Maruípe

CEP: $29.040-090$

Vitória, ES

BRAZIL

E-mail: carlosrueff@yahoo.com.br

Received: 15-08-2016

Accepted: 27-02-2017 